\title{
Psicoterapia psicanalítica e depressão de difícil tratamento: à procura de um modelo integrador
}

\author{
Júlia Trevisan*
}

\section{INTRODUÇÃO}

O pensamento psiquiátrico há muito vem tentando compreender o ser humano e seu sofrimento. A complexidade no entendimento da doença mental está possivelmente relacionada a quão difícil tem sido para a humanidade articular os conceitos de mente e de cérebro. A ciência avança de acordo com seus paradigmas, mas o ponto em comum, que definitivamente nos reúne, é a experiência clínica.

A tarefa do profissional da saúde mental é identificar o problema de seu paciente e tentar oferecer-lhe alívio, mas isso pode se tornar bastante difícil. Tanto na avaliação diagnóstica quanto na conduta terapêutica, ele se vê frente a uma ampla gama de possibilidades, todas merecedoras de atenção e estudo. Seu referencial na tomada de decisões é o científico, mas a possibilidade de pensar criticamente sua

Trabalho de conclusão do curso de Especialização em Psicoterapia de Orientação Analítica, no ano de 2003.

* Psiquiatra, Departamento de Psiquiatria e Medicina Legal, Faculdade de Medicina, Hospital de Clínicas de Porto Alegre, RS. ciência e seu entendimento do ser humano é o que traz qualidade e riqueza a seu trabalho. A tarefa diagnóstica, por exemplo, imprescindível à boa prática, possivelmente contenha algo muito mais complexo do que já conseguimos sistematizar. O mesmo se poderia dizer, conseqüentemente, da tarefa terapêutica.

Os transtornos depressivos, ainda que bem definidos fenomenologicamente, são um exemplo do quanto um grupo de afecções pode ser heterogêneo. Na prática, um caso pode tornar-se difícil não somente em função da gravidade do episódio, mas também da presença de outros fatores biológicos, psicológicos ou mesmo sociais.

As pesquisas relativas à efetividade da psicoterapia dinamicamente orientada na depressão, embora com vários resultados positivos, são inespecíficas. Seguimos nos perguntando, para este indivíduo específico, com este problema, que tipo de tratamento, realizado por quem, em que momento e sob quais condições leva a que extensão de benefício e em quanto tempo'. Enquanto nos perguntamos, a teoria psicanalítica vem nos oferecendo, desde Freud, sua contribuição. 
O presente texto faz algumas considerações sobre a relação entre a psicoterapia de orientação analítica e a abordagem de casos de "depressão difícil de tratar", revisando algumas contribuições psicanalíticas ao tema e propondo que se tente um outro olhar, além do biológico, para esses casos. Depressão de difícil tratamento pode ser toda e qualquer situação que implique uma resposta insatisfatória ao tratamento. Trata-se de um exercício construído a partir de revisão bibliográfica não-sistematizada, sobre uma dada situação prática, e a expressão "depressão de difícil tratamento", ainda que vaga, inespecífica e não familiar às classificações vigentes, é a que melhor pode representá-la, para esta autora. É descrito e comentado um exemplo clínico, a partir das contribuições da literatura psicanalítica sobre depressão.

\section{CIÊNCIA E PSICOTERAPIA}

A questão científica deve ser encarada em psicoterapia. Contudo, esta não é uma tarefa fácil. Além disso, algumas considerações devem ser feitas a fim de obtermos aplicabilidade clínica de nossas atuais, mas não eternas, "verdades científicas". Enquanto psiquiatras, somos muito mais clínicos do que cientistas e devemos aplicar em nosso trabalho um enfoque humanístico, que leva em conta o conhecimento científico de várias áreas, mas vai além disso e constitui arte ${ }^{2}$.

A pesquisa em psicoterapia vem se tornando uma área científica séria, mas alguns obstáculos já superados pelas ciências biológicas ainda não foram superados pela área da psicoterapia. Ainda que o valor do relato de caso venha sendo reafirmado ${ }^{1}$, não é mais suficiente que se afirme de colega para colega que alguém está realizando um bom trabalho terapêutico. Existem muitas dificuldades, entre elas o fato de que não conseguimos amostras homogêneas (se é que são possíveis), não dispomos de placebo e não dispomos sequer de uma linguagem comum.

Segundo Thomas Kuhn" ${ }^{3}$, "os primeiros estágios do desenvolvimento da maioria das ciências têm-se caracterizado pela contínua competição entre diversas concepções de natureza distintas, cada uma delas parcialmente derivada e todas apenas aproximadamente compatíveis com os ditames da observação e do método científico. O que diferenciou essas várias escolas não foi um ou outro insucesso do método - todas elas eram científicas - mas aquilo que chamaremos a incomensurabilidade de suas maneiras de ver o mundo e nele praticar a ciência".

$\mathrm{Na}$ psiquiatria, ainda falamos de correntes de pensamento, encontramo-nos em uma etapa pré-paradigmática ou, ainda, para Drob $^{4}$, multiparadigmática. Embora isso seja desanimador, é melhor do que estabelecer precipitadamente uma verdade, um dogma, como defesa contra a incerteza ${ }^{4,5}$.

Lipowsky² alerta para o problema do reducionismo na psiquiatria e afirma que nem um enfoque que não considere a mente nem um que não considere o cérebro pode fazer justiça à complexidade da doença mental ${ }^{2}$. O ecletismo em psiquiatria é uma necessidade. Entenda-se por ecletismo não aquele descrito como uma postura pragmática, na qual o terapeuta usa seja o que for que pensa ajudar o paciente, algo ingênuo e sem crítica, mas sim no sentido integrador, onde a pureza teórica pode ser preservada e as diferenças respeitadas $^{5,6}$. Eizirik ${ }^{7}$ sugere que se adote "uma certa neutralidade em relação às teorias que sustentam nossa prática, o que implica a admissão de um possível valor, utilidade ou complementaridade em outra teoria ou outros autores. Significa também a presença de um certo senso de humor, que decorre da capacidade de reconhecer e sorrir ante as próprias pretensões e convicções e admitir seus limites - aí incluindo o alcance explicativo das teorias".

Wallerstein ${ }^{8}$ postula que, para ser efetiva ao máximo, cada abordagem deve combinar com o paciente para quem ela é mais apropriada. Segundo Yager $^{9}$, o enfoque eclético envolve abordar cada situação clínica através de múltiplas perspectivas teóricas e estabelecer aquela mais de acordo com o que o paciente deseja e necessita, sem abrir mão da melhor informação disponível. Para este autor, o ecletismo se torna necessário pelas propriedades do nosso próprio aparato cognitivo e perceptivo, pela forma sujeita a erros como nós organizamos a realidade. Ele afirma que a perspectiva teórica, ao mesmo tempo que organiza questionamentos, observações e a compreensão, limita o campo de visão, e que as duas coisas são necessárias, porque sem um esquema para a apreciação de dados ficaríamos confusos. Observa que nós, psiquiatras, processamos a "realidade" através de nossas próprias pré-concepções, para ver coisas que correspondem à nossa forma usual de apreciar o comportamento humano e a doença, aqui incluída a depressão? . 
AS CONTRIBUIÇÕES CIENTÍFICAS SOBRE A PSICOTERAPIA DE ORIENTAÇÃO ANALITIICA NO HETEROGÊNEO GRUPO DAS DEPRESSÕES

A depressão, embora descrita fenomenologicamente de forma muito clara nas classificações atuais, apresenta-se nos mais variados contextos psicológicos, biológicos e sociais. Existem milhares de situações nas quais a depressão pode ser de difícil tratamento. Exemplos seriam quadros que preenchem critérios para depressão resistente, quadros de não-resposta ao tratamento inicial, casos onde a aderência é complicada, onde a comorbidade ou grupos sindrômicos em eixo I ou II atrapalham o tratamento, ou, ainda, situações de risco de suicídio. Além disso, variadas circunstâncias atípicas de vida e uma infinidade de situações que, em geral, tentamos incluir no modelo biopsicossocial de abordagem podem também interferir no tratamento.

Em um estudo sobre pacientes com doença mental que não apresentavam resposta após 6 meses do tratamento de rotina, dos quais $75,5 \%$ tinham diagnóstico de depressão, e que seguiam utilizando os serviços de saúde, Guthrie et al. ${ }^{10}$ encontraram resultados positivos para a intervenção psicoterápica. O estudo, focado na relação custo/benefício da psicoterapia psicodinâmica-interpessoal, concluiu que esta é uma alternativa eficiente para pacientes com sintomas duradouros, nãopsicóticos, que não respondem ao tratamento psiquiátrico convencional.

O Instituto Nacional de Saúde Mental dos Estados Unidos ${ }^{11}$ conduziu um amplo estudo sobre duas diferentes formas de tratamento da depressão (Estudo Colaborativo para o Tratamento da Depressão do NIMH). De 250 pacientes selecionados, 239 entraram no estudo e foram submetidos a quatro situações diferentes de tratamento: psicoterapia interpessoal (TIP); psicoterapia cognitivo-comportamental (PCC); imipramina e manejo clínico (IMI-MC); e placebo e manejo clínico (PLA-MC). A TIP era baseada nas idéias da escola interpessoal de psicanálise de Sullivan, nos estudos sobre o luto de Freud e na teoria do apego de Bowlby; a PCC foi representada pelas idéias de $\mathrm{Beck}^{12}$. Ao analisar a amostra total, sem levar em conta a gravidade inicial da doença, não se encontrou evidência de maior efetividade de uma das psicoterapias sobre outra, e mesmo do tratamento padrão com imipramina. Quando comparadas com placebo, houve limitada evidência de melhor desempenho da TIP e nenhuma evidência para PCC.
Avaliando exploratoriamente a variável severidade, observou-se que, para pacientes mais severamente deprimidos, houve alguma evidência da eficácia da TIP e forte evidência da eficácia da IMI-MC. Ainda, em uma observação sobre a aderência ao tratamento, interessada no significado clínico dos achados, a autora comenta que mais pacientes em TIP do que em PLA-MC permaneceram em tratamento tempo suficiente para obter melhora ${ }^{13}$.

Dentre as conclusões dos autores, contudo, está a afirmação de que um julgamento final sobre a efetividade das psicoterapias em pacientes mais deprimidos deve aguardar, e que talvez, se os pacientes fossem estudados por mais tempo, avaliando outras características da amostra (por exemplo, fatores como a personalidade), o resultado seria diferente $^{11}$. Outra observação importante é que nenhuma das terapias estudadas produziu efeitos consistentes nas medidas relacionadas às suas origens teóricas, indicando a pouca especificidade dos resultados das abordagens ${ }^{13}$.

Scott et al. ${ }^{14}$, estudando depressões crônicas, referem que se trata de um grupo muito heterogêneo de pacientes, onde vários fatores contribuem para a causa, mas que 0 papel dos eventos de vida como precipitantes ou mantenedores dos quadros indica a importância do fator psicológico no desenvolvimento da cronicidade. Scott ${ }^{15}$, revisando os tratamentos psicológicos para depressão, observou que a atitude do paciente, se ele acredita no modelo em questão e na possibilidade de melhora, influencia significativamente a resposta clínica. Ainda, a aptidão do terapeuta num dado modelo de tratamento pode corresponder a mais de $30 \%$ de variabilidade nos resultados.

Kendler et al. ${ }^{16}$, na busca de modelos etiológicos de depressão, sugerem quatro principais fatores de risco em interação: experiências traumáticas, fatores genéticos, temperamento e relações interpessoais. Os autores observaram que o estressor de vida recente foi, isoladamente, o fator de maior risco para o desenvolvimento do quadro. Além disso, os autores chamaram a atenção para a multiplicidade de interações possíveis entre os fatores, de efeito aditivo, como a existência de determinadas características que podem predispor ao estressor, além, naturalmente, da "má-sorte".

Zavaschi et al. ${ }^{17}$, revisando a literatura sobre a relação entre perdas e depressão, 
encontraram uma associação significativa entre trauma por perda de vínculos afetivos na infância e depressão na vida adulta. Nessa revisão, os autores observam que alguns têm atribuído a não-resposta terapêutica dos pacientes deprimidos a seqüelas de traumas psicológicos ocorridos na infância (Kaplan \& Klinetob apud Zavaschi ${ }^{18}$ ). Em estudo original sobre o tema, Zavaschi ${ }^{18}$ não encontrou relação positiva para perdas na infância e depressão, mas sim para outros eventos traumáticos, embora a maioria dos estudos afirme existir essa relação.

A ocorrência de depressão paralelamente a outros diagnósticos de eixo I ou II parece ser mais a regra do que a exceção ${ }^{19}$. As diferentes estruturas de personalidade e algumas subsíndromes, ainda que não se caracterizem como comorbidade, também influenciam a avaliação e o resultado do tratamento, podendo tornar a abordagem difícil. Schestatsky ${ }^{20}$, estudando depressão e comorbidade, afirma que a presença de um transtorno de personalidade associado traz maior probabilidade de suicídio, diminuição da resposta ao tratamento, menor número de remissões completas e menor readaptação social. Marcus ${ }^{21}$ propõe que, dependendo da estrutura da personalidade, a depressão terá uma apresentação diversa e que, tecnicamente, ela deve ser abordada levando isso em conta.

Grote \& Frank ${ }^{19}$, entre outros ${ }^{20,22}$, consideram crucial o papel da psicoterapia na abordagem de pacientes em contextos psicossociais específicos e na comorbidade. Essas autoras estudaram a participação de determinadas circunstâncias na depressão de difícil tratamento e concluíram pela necessidade de abordagem individualizada. Entre essas circunstâncias estão a gestação, a maternidade e também possíveis subsíndromes de pânico, fobia social e estresse pós-traumático, que influenciam a apresentação e a resposta ao tratamento.

Para Hendin ${ }^{23}$, a psicoterapia também contribui para a abordagem do paciente com risco de suicídio. O autor alerta para o fato de que o terapeuta não deve reduzir o tratamento ao manejo e controle do paciente, mas também compreender de que forma o paciente usa sua morte potencial como parte de sua adaptação, evitando armadilhas contratransferenciais e trabalhando psicodinamicamente. Situações que podem ocorrer, por exemplo, são a evitação do terapeuta em estar mais próximo ao paciente, para tentar diminuir sua culpa frente a um possível suicídio ou, ainda, a preocupação em ter sua competência em cheque. Além disso, aquele pode ver-se aprisionado, narcisisticamente, em seu desejo de conhecer e curar a todos, quando o paciente pode tê-lo escolhido como executor, e não como salvador. $\mathrm{O}$ autor ${ }^{23}$ conclui que a melhor chance de ajudar - paciente é compreender e auxiliar nos problemas que fazem-no suicida, incluindo a forma como ele usa as ameaças de morte, porque é só na psicoterapia que a natureza do envolvimento suicida se torna aparente.

Em resumo, os estudos demonstram, ainda que com limitações no que diz respeito a especificidade, que a psicoterapia é um componente essencial da resposta terapêutica na depressão e que a abordagem combinada, por exemplo, de fármacos com psicoterapia é uma prática comum e positiva ${ }^{24}$, principalmente em pacientes com formas mais crônicas e complexas da doença ${ }^{20}$.

\section{CONTRIBUIÇÕES DA TEORIA PSICANALIITICA PARA O ENTENDIMENTO DOS ESTADOS DEPRESSIVOS}

Em Luto e melancolia, Freud ${ }^{25}$ compara a melancolia ao luto, descrevendo uma sensação de dolorosa infelicidade decorrente de uma perda objetal. "Os traços mentais distintivos da melancolia são um desânimo profundamente penoso, a cessação de interesse pelo mundo externo, a perda da capacidade de amar, a inibição de toda e qualquer atividade e uma diminuição dos sentimentos de auto-estima a ponto de encontrar expressão em autorecriminação e auto-envilecimento, culminando numa expectativa delirante de punição" 25 . Contudo, na melancolia, a perda do objeto é de natureza ideal. Além de partilhar algumas características com o luto, a melancolia envolve uma regressão para a fase oral ainda narcisista da libido, onde ocorre uma identificação com o objeto perdido. "No luto, é o mundo que se torna pobre e vazio; na melancolia, é o próprio ego". É em relação à identificação regressiva que Freud ${ }^{25}$ diz: "A sombra do objeto recai sobre o ego". A libido livre, proveniente da catexia objetal, é retirada para o ego e se volta para estabelecer uma identificação do ego com o objeto. Por ser julgado como se fosse um objeto, parte do ego se coloca contra outra, julgando-a criticamente. As auto-recriminações vistas clinicamente são recriminações feitas a um objeto amado que foram deslocadas. Objeto e ego sucumbem ao julgamento do chamado, na ocasião, "agente crítico" ${ }^{25}$. Vale observar que, no luto, a perturbação da auto-estima está ausente. 
Freud salienta também a ambivalência como fator predisponente à condição, onde a relação com o objeto se caracteriza por amor e ódio. A autotortura, vista clinicamente, é explicada por meio de tendências a sadismo e ódio relacionados ao objeto e que retornam ao próprio eu do indivíduo. Aqui existe uma correção da consideração anterior sobre o destino da catexia objetal, ou seja, é só uma parte da catexia objetal que se desloca para a identificação. A outra parte, devido à ambivalência, encontra-se no sadismo. Também o suicídio abriga impulsos assassinos contra outros. O ego só pode se matar se, devido ao retorno da catexia objetal, puder tratar a si mesmo como um objeto ${ }^{25}$.

Segundo Abraham ${ }^{26}$, considerando-se as fases do desenvolvimento libidinal propostas por Freud, o inconsciente encara a perda de um objeto como um processo anal, e sua introjeção como um processo oral. Sobre a fase sádicoanal da libido, o autor discorre sobre o componente instintivo do sadismo, mostrando em ação duas tendências opostas de prazer. Uma delas é destruir o objeto (ou o mundo externo); a outra é controlá-lo. Ao se referir à melancolia e à neurose obsessiva em um mesmo capítulo, Abraham propõe que se examine a fase sádico-anal em dois estágios. No nível posterior, predominam as tendências conservadoras, de reter e controlar, e no nível mais antigo, as tendências hostis ao objeto, de destruí-lo ou perdê-lo. O neurótico obsessivo regride para o nível posterior desses dois planos, sendo capaz de manter contato com seu objeto. O melancólico, entretanto, assim que seu ego entra em conflito com seu objeto de amor, abandona sua relação com esse objeto, colocando em ação as tendências do nível mais antigo.

Abraham ${ }^{26}$ postulou a importância da fase oral para a melancolia. Uma fixação especial da libido na fase oral foi considerada por ele como um dos fatores implicados na etiologia da doença. O processo de introjeção no melancólico, representante da incorporação oral, repousa num grave conflito de sentimentos ambivalentes. Outros fatores implicados na etiologia, segundo este autor, são a ocorrência do primeiro desapontamento com o objeto de amor antes que os desejos edipianos sejam superados e a repetição desse desapontamento primário na vida ulterior, além de uma grave lesão ao narcisismo infantil. Sobre a psicogênese da melancolia, Abraham ${ }^{26}$ lembra como os pacientes melancólicos são inacessíveis a qualquer crítica de seu modo de pensar. Neles, vê-se o caráter narcísico do pensamento e o desprezo por pessoas que os confrontam com a realidade.

Resumindo, "quando as pessoas melancólicas sofrem uma decepção insuportável por parte de seu objeto de amor, elas tendem a expelir esse objeto como se fosse fezes, e a destruí-lo. Logo após, realizam o ato de introjetá-lo e devorá-lo, ato que é uma forma especificamente melancólica de identificação narcísica. Sua sede sádica de vingança encontra, então, satisfação, atormentando o ego, atividade que, em parte, dá prazer"26.

Melanie Klein ${ }^{27}$ postula que o indivíduo deprimido não estabeleceu bons objetos internos e que não se sente seguro em seu mundo interno mediante a perda externa. Em $1934^{27}$, com A contribution to the psychogenesis of manic depressive states, a autora desenvolve o conceito de posição depressiva, definida como a fase do desenvolvimento na qual o bebê reconhece um objeto inteiro e se relaciona com ele. Aqui, observa que surgem novos sentimentos, de falta e de desejo pelo objeto bom que, na fantasia, foi destruído e perdido, bem como a culpa decorrente disso. Em Mourning and its relation to manic depressive states $^{28}$, de 1940, menos se fala em regressão oral e mais se enfoca o conceito de posição depressiva como um evento que modifica o desenvolvimento, através do qual ocorrem as mudanças necessárias à adaptação. É como se a criança passasse por algo semelhante ao luto, e a negociação satisfatória nesse momento, com o estabelecimento de bons objetos internos, determinará o curso futuro da doença mental e, particularmente, a vulnerabilidade para depressão frente a futuras perdas. A essência do conceito de posição depressiva é conter o início do processo de internalização de bons objetos totais, algo que nunca se encerra, acompanhando o indivíduo ao longo da $v^{2} a^{28}$. Se a preocupação com o objeto predomina, a culpa levará à tentativa de reparação. Se o narcisismo predomina, os mecanismos psíquicos não levarão em consideração o objeto e irão em busca da autovalorização ${ }^{29}$.

A visão de Edith Jacobson apud Lund ${ }^{30}$ sobre a depressão psicótica salienta, entre outras questões, que, nos humores depressivos, diferencia-se a predominância de derivados de impulsos agressivos. Há uma fusão do self e da representação objetal dentro do ego e superego, trazendo o ataque de um superego altamente patológico, sádico, idealizado sobre um self fusionado e altamente 
desvalorizado. A capacidade para a tristeza está ausente, porque o objeto e sua representação estão desvalorizados e unidos à representação desvalorizada do self. Jacobson confirma a predominância de conflitos oraissádicos e a intensa dependência de objetos amados, odiados e idealizados, e propõe que as principais ansiedades e conflitos na depressão são o medo do abandono do objeto e das conseqüências da agressão a ele dirigida ${ }^{30}$.

Já Brenner ${ }^{31}$ entende que existem dois tipos de desprazer, a ansiedade e o afeto depressivo, que podem decorrer de situações como perda do objeto, perda do amor do objeto, castração ou punição. No caso da ansiedade, a situação é apenas temida, e no afeto depressivo, é um evento de vida. Este autor se posiciona dizendo que o que importa é compreender a natureza da formação de compromisso e o conflito subjacente. Para ele, sofrimento ou afeto depressivo não é necessariamente perda do objeto ou agressão voltada ao ego através da identificação, ou sinônimo de assumir que a predominância dos conflitos são da fase oral, baseados em traumas pré-edípicos. Ele postula que o afeto depressivo desempenha o mesmo papel na psicopatologia do que a ansiedade, sendo uma parte inevitável da vida mental, funcionando como gatilho de defesas e conflitos, podendo ou não ser consciente em uma dada formação de compromisso ${ }^{31}$.

Bleichmar ${ }^{29}$ define a essência dos transtornos depressivos como a sensação de impotência e desesperança de realizar um desejo no qual o sujeito está intensamente fixado. Essa sensação dá colorido a toda a auto-representação, e o self se vê inferior, incapaz, fraco, impotente e ameaçado.

Entre outras tentativas de sistematizar o conhecimento acerca da psicopatologia dos estados depressivos estão as considerações sobre o narcisismo patológico. Nesse caso, um estado depressivo surge sempre que houver decepção tanto da parte do ego ideal, herdeiro direto do narcisismo, como do ideal de ego (imago parental idealizada). O indivíduo se sente em um permanente estado de sobressalto diante da possibilidade de não corresponder às exigências provindas de dentro ou de fora de si mesmo ${ }^{32,33}$.

Quanto à auto-estima, Pedder ${ }^{34}$ lembra ser a sensação do self de ser estimado e valorizado por seus objetos internos, sejam eles chamados de "agente crítico", superego ou imago parental. A expressão se refere a uma relação objetal interna, a estima que uma parte do self tem por outra. Para Marcus ${ }^{21}$, o sistema da auto-estima tem um papel central na vulnerabilidade à depressão, e o grau em que a depressão afeta a auto-estima depende não só da gravidade da doença mas também da estrutura de personalidade pré-mórbida.

Mais recentemente, outros autores vêm tentando diferenciar dois tipos de depressão, baseando-se, em parte, nos escritos de Freud sobre os processos de incorporação oral e formação do superego, considerando não ser interessante integrar esses dois mecanismos de fases tão distintas do desenvolvimento psíquico ${ }^{35}$. Postula-se que exista uma depressão anaclítica, focada em questões interpessoais como dependência, desamparo, sensação de perda e abandono, e outra chamada introjetiva, derivada de um superego punitivo e cruel, focada em questões de autocrítica, preocupações com valor pessoal e sensação de culpa e fracasso ${ }^{35}$.

A depressão anaclítica ou dependente é caracterizada por sentimentos de solidão e desamparo e pela busca de alguém que venha preencher o vazio da mãe original ${ }^{33}$. Para esse sujeito, que deseja profundamente cuidado e amor, a separação ou a perda objetal traz medo, apreensão e mecanismos primitivos de defesa. A depressão introjetiva ou autocrítica é caracterizada por sentimentos de desvalia, inferioridade, fracasso e culpa. O indivíduo se auto-avalia constantemente de forma cruel e tem um medo crônico da crítica ou nãoaprovação alheia. É exigente, competitivo, busca aprovação e reconhecimento e, em geral, consegue boas realizações, obtendo, contudo, pouca satisfação.

É interessante observar que a resposta ao tratamento muda nos dois grupos. O grupo dos autocríticos responde melhor às abordagens psicodinamicamente orientadas do que às intervenções breves ${ }^{35}$. Esses indivíduos têm mais risco para sérias tentativas de suicídio, seu sentimento de culpa se satisfaz na enfermidade, podem negar-se o direito de melhora e apresentar a chamada reação terapêutica negativa ${ }^{33,36}$.

\section{VINHETA CLÍNICA}

\section{Ana, 38 anos}

Ana veio encaminhada para seguimento ambulatorial clínico e psicoterápico há 4 meses, após sua terceira internação psiquiátrica por tentativa de suicídio. Apresentava, na ocasião, alterações de peso e apetite, insônia, 
desesperança, desvalia, afeto lábil, humor triste e irritável, sensação de estar perdida no mundo, só, referindo que, apesar de não estar como antes, pensando em se matar, não via outras perspectivas para si a não ser morrer. Dizia-se incapaz de pensar, colocando que ora sentia-se aérea, como que anestesiada, ora vinha-Ihe um desespero, um sofrimento intenso que the conduzia às idéias de morte. De fato, parecia alheia e incapaz de tomar contato com seus sentimentos ou falar de suas circunstâncias de vida. Nos últimos anos, dizia-se incapaz de estar com os familiares. Falava que sua relação conjugal se desgastara, que não suportava as dificuldades no cuidado com os filhos de 4, 9 e 16 anos e que seus pais eram intrusivos e críticos. Também via-se incapaz de assumir seus compromissos profissionais.

Os sintomas depressivos tomaram vulto após o nascimento de seu filho mais jovem. Vinha de um período de desgaste por formação superior e doença física que lhe trouxe sérios problemas devido a complicações decorrentes do uso de corticóides, quando engravidou, sem planejamento, já com seu casamento em conflito. $\mathrm{Na}$ época, conta que pretendia, "com seus filhos já mais crescidos", "viver sua vida", ter mais satisfações em seus relacionamentos, etc. O puerpério foi complicado, o bebê tinha problemas clínicos que dificultavam a alimentação e o sono. Sentia-se sobrecarregada, incapaz de lidar com suas tarefas de mãe. Tentou vários fármacos para tratamento dos sintomas depressivos e esteve hospitalizada em serviços de reconhecido valor técnico e acadêmico. Estava em uso de venlafaxina.

Sua vida familiar, ocupacional e social encontrava-se em total desordem, vivendo longe da família, de sua cidade, em licença ocupacional. Vivia longe de casa nos últimos 2 anos, residindo com uma prima, mantendo um relacionamento extraconjugal, que considerava ser "seu único momento bom". Suas internações coincidem com esse período. O esposo passava viajando a trabalho, seu filho adolescente ficava em sua casa, procurando autogerenciar-se, e os mais jovens estavam sob os cuidados de familiares.

Inicialmente, combinamos uma avaliação pormenorizada, que se prolongou devido à característica caótica do contexto familiar e de suporte. Foram necessários cuidados para estabelecer recursos em casos de riscos e combinações para a manutenção do tratamento, incluindo auxílio para organizar a limitação dos recursos financeiros, o que exigiu a presença de um familiar fora do grupo primário, mas disponível. Durante este período, Ana se mostrou determinada a se tratar, parecendo acreditar na proposta de atendimento, e, apesar de suas dificuldades, colaborou na organização do contrato terapêutico. A medicação foi mantida, considerando que se constituía em indicação adequada, dadas as tentativas prévias, focando-se este momento do tratamento na questão psicodinâmica.

Em sua evolução, começou a trazer material relativo a suas relações interpessoais e sua história de vida, descrevendo a mãe como alguém extremamente invasiva e o pai como frio, distante e muito crítico. Tornaram-se evidentes seus sentimentos agressivos em relação aos familiares, suas expectativas de atenção e cuidado, sua sensação de esgotamento e desconforto com as exigências da função materna e preocupações de cunho recriminatório.

\section{COMENTÁRIOS}

A depressão de Ana, já de curso prolongado, com sérios prejuízos ao funcionamento familiar, social e ocupacional, apresentava melhora apenas limitada, caracterizando um quadro de difícil tratamento. A presença de fatores psicológicos influenciando a evolução sugeriu a abordagem psicodinâmica.

Dentre vários fatores possivelmente implicados no caso de Ana, alguns se tornaram mais evidentes no início do processo. Sua incapacidade de pensar, resultante de um seqüestro, talvez seja uma estratégia defensiva para abolir o funcionamento mental, já que a realização do desejo não pôde ser alcançado. O desejo aqui pode ser apenas um ideal, uma abstração que fica no lugar do objeto. Seu ego, identificado com o objeto ausente, fica pobre e vazio. Evidencia-se a desvalia e a impotência diante do inalcançável. Talvez uma repetição do inalcançável desejo de amor do pai, figura que descreve como fria e extremamente crítica.

Seus sentimentos agressivos, sua hostilidade, sua raiva de tudo e todos são marcantes e lembram por que a agressão é tida por muitos autores como um componente essencial dos quadros depressivos - nesse caso, talvez inata, talvez em resposta a uma perda objetal, ou ambas. Suas idéias de morte representam o desejo de matar seu objeto. $O$ sadismo está aí representado tanto na agressão ao objeto introjetado quanto no impacto que essas atitudes suicidas têm em seus familiares. 
Ana abandona suas relações com o objeto e se sente "só, perdida no mundo". Na verdade , ela tem expectativas de atenção e cuidado e busca um substituto para isso, na figura do amante. Recrimina-se por abandonar os filhos, mas, antes de mais nada, talvez se recrimine, questionada por seu superego, pela intensidade de seus sentimentos agressivos, que lhe provocam culpa.

Em sua evolução, Ana ainda menciona os temas de morte, mas de forma menos freqüente. À medida que o trabalho progride, parece menos prejudicada cognitivamente, mais capaz de realizar auto-observação, recuperando partes suas inibidas defensivamente, e isso parece aliviá-la. Vem falando sobre a falta que sente dos filhos, sobre não se sentir capaz de assumir sua vida novamente e "enfrentar as cobranças dos pais e do esposo". Está melhor, ainda que parcialmente, dos sintomas depressivos, pensando se deve mudar suas sessões para dias consecutivos a fim de estar mais freqüentemente com os filhos. Mantém-se com a mesma medicação antidepressiva.

O encaminhamento da paciente para tratamento combinado parece ter resultado de uma visão mais abrangente de sua doença. Ainda que múltiplas vias ainda não compreendidas possam estar envolvidas na psicopatologia da paciente, a tarefa segue sendo a possibilidade de ficar atento a essa amplitude de vértices, tanto dentro da teoria psicanalítica quanto em relação aos entendimentos da psiquiatria clínica.

\section{CONCLUSÃO}

A respeito de psicoterapia e depressão, vale repetir Freud ${ }^{25}$ em sua ressalva de que a melancolia não é um grupo homogêneo de afecções e que provavelmente envolve mais de uma etiologia, para depois tomarmos proveito da teoria psicanalítica, ampliando nossa visão acerca dos estados depressivos.

Embora os conceitos biológicos e a abordagem farmacológica da depressão de difícil tratamento sejam essenciais, devemos pensar de forma mais abrangente, num enfoque mais individualizado sobre a doença ${ }^{19}$. A ciência parte de nossa capacidade de fazer perguntas, inclusive acerca dela própria, devendo ser usada de forma a ampliar - e não encerrar - o conhecimento. Este é um bom princípio para nortear nossa prática clínica frente ao heterogêneo grupo dos pacientes com ecletismo possam ser melhor demonstrados no manejo dos "casos difíceis", isto é, daqueles que não respondem à estratégia inicial de tratamento, quando a habilidade de repensar o problema, mudar o sistema conceitual e encontrar novas formas de abordagem pode teoricamente aumentar a probabilidade de um resultado efetivo. Contudo, se falta ao psiquiatra flexibilidade para mudar sua perspectiva teórica ou, ainda, conhecimento suficiente das alternativas, um paciente pode ser desnecessariamente tratado por um método inapropriado ou dado prematuramente como "refratário".

Apesar das limitações de nossa ciência, fica evidente que a teoria psicanalítica é rica em contribuições ao tema, e a psicoterapia de orientação analítica pode ser extremamente útil na abordagem de casos de depressão de difícil tratamento. A autora acredita que o paciente, antes de mais nada, é o sinalizador do que faz sentido.

\section{Agradecimento}

Ao Dr. Cláudio Laks Eizirik, pelo apoio recebido.

\section{REFERÊNCIAS BIBLIOGRÁFICAS}

1. Kächele $H$, Kordy $H$. Sobre os resultados das psicoterapias. Rev Psiquiatr RS 1993;15:79-96.

2. Lipowski ZJ. Psychiatry: mindless or brainless, both or neither? Can J Psychiatry 1989;34:249-54.

3. Kuhn TS. Introdução: um papel para a história. In: Kuhn TS. A estrutura das revoluções científicas. $3^{\underline{a}}$ ed. São Paulo: Perspectiva; 1994. p.19-28.

4. Drob SL. The dilemma of contemporary psychiatry. Am J Psychother 1989;43:54-67.

5. Osório $\mathrm{CM}$, Seixas $\mathrm{PHG}$, Wainstein M, Hidalgo MLP, Ferreira LC, Netto M, et al. Unidade e diversidade na psiquiatria, perspectivas da integração do pensamento psiquiátrico. J Bras Psiquiatr 1993;42:133-7.

6. Albeniz A, Holmes J. Psychotherapy integration: its implications for psychiatry. Br J Psychiatry 1996;169:56370.

7. Eizirik CL. Perspectivas de integração do pensamento psiquiátrico. Rev Psiquiatr RS 1993;15:11-5.

8. Wallerstein R. Forty two lives in treatment. New York: Guilford Press; 1986.

9. Yager J. Psychiatric eclecticism: a cognitive view. Am J Psychiatry 1977;134:736-41.

10. Guthrie E, Moorey J, Margison F, Barker H, Palmer S, McGrath G, et al. Cost-effectiveness of brief psychodynamic-interpersonal therapy in high utilizers of psychiatric services. Arch Gen Psychiatry 1999;56:51926

11. Elkin I, Shea T, Watkins JT, Imber SD, Sotsky SM, Collins JF, et al. National Institute of Mental Health Treatment of Depression Collaborative Research Program. General effectiveness of treatments. Arch Gen Psychiatry 1989;46:971-82. 
12. Schestatsky S, Fleck M. Psicoterapia das depressões. Rev Bras Psiquiatr 1999;21:41-7.

13. Elkin I. The NIMH treatment of depression collaborative research program: where we began and where we are. In: Bergin AE, Garfield SL, editors. Handbook of psychotherapy and behavior change. 4th ed. New York: John Wiley and Sons; 1994. p.114-39.

14. Scott J, Barker WA, Eccleston D. The Newcastle chronic depression study. Patient characteristics and factors associated with chronicity. Br J Psychiatry 1988;152:2833.

15. Scott J. Psychological treatments for depression. An update. Br J Psychiatry 1995;167:289-92.

16. Kendler KS, Kessler RC, Neale MC, Heath AC, Eaves LJ. The prediction of major depression in women: toward an integrated etiologic model. Am J Psychiatry 1993;150:1139-48.

17. Zavaschi MLS, Satler F, Poester D, Vargas CF, Piazenski $\mathrm{R}$, Rohde LAP, et al. Associação entre trauma por perda na infância e depressão na vida adulta. Rev Bras Psiquiatr 2002;24:189-95.

18. Zavaschi MLS. Associação entre depressão na vida adulta e trauma psicológico na infância [dissertação]. Porto Alegre: Universidade Federal do Rio Grande do Sul; 2003.

19. Grote NK, Frank E. Difficult-to-treat depression: the role of contexts and comorbidities. Biol Psychiatry 2003;53:660-70.

20. Schestatsky SS. Comorbidade entre depressão e transtornos de personalidade. Programa de educação continuada. Porto Alegre: Associação Brasileira de Psiquiatria; 1998

21. Marcus ER. Integrating psychopharmacotherapy, psychotherapy, and mental structure in the treatment of patients with personality disorders and depression. Psychiatr Clin North Am 1990;13:255-63.

22. Shepard JK. Depression: when is psychotherapy not enough? Psychiatr Clin North Am 1990;13:241-55.

23. Hendin H. Psychotherapy and suicide. Am J Psychother 1981;35:469-80.

24. Frey BN, Mabilde LC, Eizirik CL. A integração da psicofarmacoterapia e psicoterapia de orientação analítica: uma revisão crítica. Rev Bras Psiquiatr 2004;26:118-23.

25. Freud S. (1917). Luto e melancolia. In: Edição standard brasileira das obras completas de Sigmund Freud. Rio de Janeiro: Imago; 1976. vol.14, p.271-91.

26. Abraham K. (1924). Breve estudo do desenvolvimento da libido, visto à luz das perturbações mentais. In: Teoria psicanalítica da libido. Rio de Janeiro: Imago; 1970. p.81160.

27. Klein M. (1934). A contribution to the psychogenesis of manic-depressive states. In: Contributions to psychoanalysis. London: Hogarth Press; 1950. p.282310.

28. Klein M. (1940). Mourning and its relation to manicdepressive states. In: Contributions to psychoanalysis. London: Hogarth Press; 1950. p.311-8.

29. Bleichmar HB. Some subtypes of depression and their implications for psychoanalytic treatment. Int $J$ Psychoanal 1996;77:935-61.

30. Lund C. Psychotic depression: psychoanalytic psychopathology in relation to treatment and management. Br J Psychiatry 1991;158:523-8.

31. Brenner C. A psychoanalytic perspective on depression. JAPA 1991;39:25-43.

32. Stone L. Psychoanalytic observations on the pathology of depressive illness: selected spheres of ambiguity or disagreement. JAPA 1986;34:329-62.
33. Zimermam DE Depressões In: Fundamentos psicanalíticos: teoria, técnica e clínica - uma abordagem didática. Porto Alegre: Artmed; 1999. p.217-25.

34. Pedder JR. Failure to mourn, and melancholia. $\mathrm{Br} \mathrm{J}$ Psychiatry 1982;141:329-37.

35. Blatt SJ. Contributions of psychoanalysis to the understanding and treatment of depression. JAPA 1997;46:723-52.

36. Etchegoyen $\mathrm{RH}$. A reação terapêutica negativa. In: Fundamentos da técnica psicanalítica. $2^{\mathrm{a}}$ ed. Porto Alegre: Artmed; 1989. p.435-40.

\section{RESUMO}

A depressão envolve um grupo heterogêneo de situações, sendo que algumas se apresentam como de difícil tratamento. A psicoterapia psicanalítica e suas formulações teóricas têm sido muito úteis na compreensão e no tratamento da depressão. Este artigo propõe que isso é particularmente verdadeiro para os casos difíceis, quando uma perspectiva integradora pode melhorar a resposta clínica. É feita uma revisão da literatura sobre psicoterapia psicanalítica na depressão.

Descritores: Depressão, transtorno depressivo, psicanálise, terapia psicanalítica, psicoterapia.

\section{ABSTRACT}

Depression is associated with a heterogeneous group of situations, some of which may be difficult to treat. Psychoanalytic psychotherapy and its theoretical formulations have been extremely useful in the understanding and treatment of depression. The author suggests that this is particularly true in difficult-to-treat cases, when an integrative perspective may improve clinical response. The article reviews the literature on psychoanalytic psychotherapy in the treatment of depression.

Keywords: Depression, depressive disorder, psychoanalysis, psychoanalytic therapy, psychotherapy.

Title: Psychoanalytic psychotherapy and difficult-totreat depression: towards an integrative model

\section{RESUMEN}

La depresión abarca un grupo heterogéneo de situaciones, habiendo algunas que se presentan como siendo de más difícil tratamiento. La psicoterapia psicoanalítica y sus formulaciones teóricas han sido muy útiles para la comprensión y el tratamiento de la depresión. El siguiente artículo propone que eso es particularmente verdadero para los casos más difíciles, cuando una perspectiva integradora puede mejorar la respuesta clínica. Se hace una revisión de la literatura sobre psicoterapia psicoanalítica en la depresión 
Palabras clave: Depresión, trastorno depresivo, psicoanálisis, terapia psicoanalítica, psicoterapia.

Título: La psicoterapia psicoanalítica y la depresión de difícil tratamiento: búsqueda por un modelo integrador
Correspondência:

Dra. Júlia Trevisan

Rua Dr Dias de Carvalho, 340/402 - Bairro Tristeza.

CEP 91910270 - Porto Alegre - RS

Fone: (51) 9969.5703

E-mail: julia.t@terra.com.br

Copyright (C) Revista de Psiquiatria

do Rio Grande do Sul - SPRS 